\title{
RELIGIÓN Y POLÍTICA: LA RESPUESTA DE LA FILOSOFÍA DE HEGEL ENTRE TENSIÓN Y RECONCILIACIÓN*
}

\author{
MONTSERRAT HERRERO \\ Instituto Cultura y Sociedad/Departamento de Filosofía \\ Universidad de Navarra
}

\begin{abstract}
RESUMEN: La tensión entre el poder de la comunidad política y la conciencia religiosa es una constante en el pensamiento y la acción políticos. El presente artículo toma pie en la reflexión filosófica de Hegel para dilucidar el porqué de esta tensión y la complejidad de su posible solución. ¿Cómo abordar la intrincada relación entre los diferentes momentos de manifestación del espíritu, como espíritu subjetivo, espíritu objetivo y espíritu absoluto, en la que está implicada la relación entre religión y política en la filosofía de Hegel? He elegido un lugar dentro del sistema hegeliano para realizar este abordaje: la conciencia moral. El tratamiento de esta figura del espíritu permite abordar la relación entre religión y política en el contexto del sistema hegeliano de un modo original y clarificador.
\end{abstract}

PALABRAS CLAVE: Hegel, religión, política, conciencia moral.

\section{Religion and the Political: \\ The Answer of Hegel's Philosophy between Tension and Reconciliation}

ABSTRACT: A tense relationship between politics and the religious conscience is a constant in political thinking and action. This article deals with Hegel's philosophy in order to clarify the reasons for that tension and the complexity of the possible solution. How is the way to approach the intricate relationship between the different ways of manifestation of the spirit -as subjective, objective and Absolut Spirit that are implicated in the relationship between religion and politics in Hegel's Philosophy? I have chosen a place inside the Hegelian's system to approach this question: the moral conscience. The analysis of this shape of the Spirit allows an original perspective on this topic.

KEY WORDS: Hegel, religion, politics, moral conscience.

La conexión entre religión y política se ha convertido en un tema controvertido en nuestros días, tanto como lo pudo ser al comienzo de la modernidad. La eliminación de la tensión entre la libertad subjetiva y la comunidad política parece haber sido uno de los grandes logros de la modernidad política. Con él, una vez desvinculado de sus raíces religiosas, comienza el imperio de las luces, que conducirá primero a la revolución y después a la ideología liberal.

Sin embargo, hasta qué punto la religión supone una defensa de la libertad subjetiva frente al siempre potencial totalitarismo del poder político sigue siendo una cuestión abierta. No en vano las comunidades políticas luchan por neutralizar la esfera pública en términos religiosos para no

Agradezco los comentarios a este texto —en la presentación oral que hice de él en el Ethics and Society Forum dirigido por D. Thunder en el Instituto Cultura y Sociedad- de Alejandro Vigo y José Ignacio Murillo, que han contribuido a clarificarlo y a mejorarlo. 
encontrar ninguna competencia a su poder. La cuestión es hasta qué punto esa neutralización se hace para liberarse de los poderes indirectos de las iglesias y consolidar así el monopolio del poder político, o si realmente se hace para disminuir la conciencia de libertad de los individuos y hacerlos así más obedientes al Estado. El presente artículo toma pie en la reflexión filosófica de Hegel para dilucidar el porqué de esta tensión entre el poder de la comunidad política y la conciencia religiosa y la complejidad de su posible solución ${ }^{1}$, que no es la mera reconciliación de la religión y la política por mediación de la filosofía y, por tanto, la realización aproblemática del Estado protestante, aunque los textos hegelianos nos pudieran conducir fácilmente hasta esta conclusión.

En sus primeros escritos sobre la religión ${ }^{2}$ la preocupación de Hegel se centraba en la relación entre la subjetividad de la religión que está bajo el dominio de una ley abstracta y la configuración política de un Estado plenamente objetivo, libre del arbitrio de un querer individual, tal como se daba en las religiones civiles de la antigüedad. La preocupación teológico-política del joven Hegel, por tanto, gira en torno a la reconciliación del espíritu subjetivo y del espíritu

1 En los últimos años este tema ha sido revitalizado en la bibliografía sobre Hegel. Es de destacar en español el volumen editado hace ya algunos años por Paredes, M. C. , Política y religión en Hegel, Universidad de Salamanca, 1995, que ha sido considerado en este artículo en los textos más cercanos a mi interés. También en español hay que poner de relieve el magnífico artículo de A. Ginzo, «Política, religión y filosofía en G. W. F. Hegel», en Revista de Estudios Políticos, 94 (1996), pp. 111-145. En lengua francesa ha aparecido recientemente Palacio, F., Hegel. La religión et le politique, Ellipses, Paris, 2012. Este estudio mira la problemática entre religión y política desde la perspectiva de la filosofía de la religión. Un año antes había aparecido Lewis, T. A., Religion, Modernity and Politics in Hegel, Oxford University Press, Oxford, 2011. El libro de Lewis intenta colocar la religión en un lugar central en el conjunto del sistema de Hegel, puesto que en su opinión es un tema que ha sido muy descuidado en la bibliografía. Argumenta que la posición que sustenta Hegel es mejor que cualquiera de las posibilidades abiertas en nuestros días por la filosofía política: sea la casi total laïcité por un lado o la teocracia por el otro (pp. 9-10 y 244-247). Este libro hay que enmarcarlo dentro de lo que pudiera denominarse una lectura kantiana de Hegel en la que se desempeña una cierta tradición angloamericana, como es el caso de R. Pippin o T. Pinkard. En ese mismo año se edita un libro por ŽıžEK, S., CROCKETT, C., DAVIS, C., Hegel \& the infinite: religion, politics, and dialectic, Columbia University Press, New York, 2011. Existe también en lengua inglesa el volumen editado por A. Nuzzo, Hegel on religion and politics, State University of New York Press, Albany, 2013. Este volumen intenta traer la argumentación hegeliana a nuestro tiempo y enfrenta los argumentos de entonces con cuestiones cruciales para nuestro presente relativas a la relación entre religión y política. Todos estos escritos abordan la problemática situación de la religión en el sistema de Hegel, que atañe tanto al espíritu subjetivo, como al espíritu objetivo y al espíritu absoluto. En ellos se toman diferentes puntos de vista para abordar esa relación. Todos ellos han esclarecido muchos aspectos de esta relación. Lo original de este artículo es la perspectiva desde la que se intenta comprender la intricada relación entre religión y política en la filosofía de Hegel, a saber, la conciencia moral. La actualidad de este planteamiento viene de que es en este lugar donde se presenta actualmente de manera eminente el problema teológico-político.

2 Disponemos ahora de la magnífica edición de G. Amengual: G. W. F. Hegel, Escritos sobre religión, Sígueme, Salamanca, 2013. 
objetivo. Con la progresiva elaboración del sistema, sin embargo, la tensión relevante para comprender la adecuada relación entre religión y política se irá perfilando como una relación entre el espíritu absoluto y el espíritu objetivo que quiere definirse en la forma de una reconciliación en el Estado protestante ${ }^{3}$.

¿Cómo entender en este contexto la transformación de la tensión entre esas dos manifestaciones del espíritu en reconciliación? La interpretación se ha hecho eco en ocasiones desde un posible cambio de posición de Hegel respecto de este punto ${ }^{4}$. Inicialmente parece más convincente la posición, por ejemplo de F. Wagner ${ }^{5}$, quien aconseja distinguir los planos en los que Hegel aborda esa tensión; muy en particular, el plano de la filosofía de la historia y el de lo que él denomina, la teoría institucional.

Efectivamente, la relación entre religión y política aparece, por un lado, como una relación entre el espíritu subjetivo y el espíritu objetivo, así en la Filosofía del Derecho. En la Enciclopedia y en las Lecciones sobre filosofía de la religión, sin embargo, la perspectiva en la que se aborda esta cuestión es la relación entre el espíritu objetivo y el espíritu absoluto. Un punto de vista diferente incluso sería el de la Fenomenología del Espíritu donde la religión aparece culminando el proceso de constitución del espíritu y donde, para

3 Como bien señala G. Amengual, a partir de la Enciclopedia de Heidelberg (1817), el lugar sistémico de la religión es el espíritu absoluto: cfr. Introducción en G. W. F. Hegel, Escritos sobre religión, p. 25.

4 Es la opinión de W. JAESChKe, en «Staat aus christlichem Prinzip und christlicher Staat», en: Der Staat 18 (1979), (pp. 349-374), p. 356. También es la opinión que manifiesta A. Ginzo en el artículo citado, p. 133. El clarificador artículo citado de A. Ginzo, expone las líneas generales de la evolución de la relación entre religión y política, mediada por la filosofía, en el pensamiento de Hegel. Su tesis, en una correcta exégesis de los textos hegelianos, parece inapelable. Señala también una evolución desde los primeros escritos de juventud en los que Hegel se siente fascinado por una religión civil, hasta los escritos posteriores en los que tomando pie del gran principio del cristianismo reformado pasa a una visión en que la filosofía ha de mediar la relación entre religión y política. En cualquier caso, de un modo diferente en la Filosofía del derecho y en la Enciclopedia y la Filosofía de la religión. Hegel evoluciona en estas obras desde el punto de vista de una deseable separación entre la iglesia y el Estado, tal como aparece en la Filosofía del derecho, hasta una deseable absoluta reconciliación entre ambos en el horizonte del Estado protestante. Esta es la tesis de Ginzo, por otro lado, corroborada en prácticamente toda la bibliografía. Mi artículo toma el punto de vista de la conciencia moral y desde ella como nudo en el que se reflejan los diferentes aspectos del espíritu es posible percibir las tensiones entre religión y política subyacentes a la filosofía de Hegel. Unas tensiones que no son superables mientras la historia siga abierta. La historia es el único lugar por donde el sistema de Hegel no cierra. Estoy de acuerdo, sin embargo, con la conclusión de Valls Plana de que Hegel no niega nunca en este punto sus posiciones anteriores. Simplemente se va fijando en diferentes aspectos de la relación entre política y religión. R. Valls Plana, «La nota al § 552 de la Enciclopedia de las ciencias filosóficas de Hegel (3 ${ }^{a}$ edición, 1830) sobre religión y Estado», en: Paredes, M. C. , Política y religión en Hegel, Universidad de Salamanca, 1995 (pp. 143-158), p. 156.

5 Wagner, F., «Religion zwischen Rechtfertigung und Aufhebung. Zum systematischen Ort von Hegels Vorlesungen über die Philosophie der Religion», en: HeinRich, D. u. Horstmann, R.-P. (Hrsg.), Hegels Logik der Philosophie. Religion und Philosophie in der Theorie des absoluten Geistes, (pp. 127-151). 
el tema que nos interesa, la conciencia moral se mediatiza con la conciencia religiosa. Finalmente, en la Filosofía de la Historia aparece el despliegue histórico de esa relación, que alcanza su reconciliación en la forma del Estado protestante. El curso de la historia recorre tres etapas diferenciadas de la relación entre religión y política: una primera, en la que aparecen como una unidad indiferenciada y que se corresponde con las religiones políticas; una segunda, de diferenciación, que se corresponde con el tiempo que antecede a la reforma y que tiene su cúspide en el principio católico; y una tercera, que es la de la unidad característica de la época moderna y que se aviene a la conciencia protestante. El proceso histórico manifiesta temporalmente la estructura racional verdadera de la relación entre religión y política. Esta estructura racional verdadera - y no su proceso histórico- correspondiente a la modernidad política es la que degranarán las páginas que siguen en compañía de los textos de Hegel.

El desconocimiento por parte del mundo antiguo de la diferencia entre religión y política alimentó durante siglos el imperialismo, fuera este religioso o político. Tanto en los Principios de la Filosofía del Derecho § 270, como en la Enciclopedia § 552, rechaza Hegel con múltiples argumentos esta posibilidad. La diferenciación de la esfera religiosa y la política surge en la historia con el cristianismo. A este momento pertenece lo que Hegel denomina «la abstracción católica». El catolicismo instala la objetividad en el corazón de la subjetividad y, en consecuencia, en el seno de toda práctica religiosa, quedando así aislada del ámbito de la eticidad, pero además y, esto es lo peor, en su opinión, cosifica el espíritu en su concepción de los sacramentos ${ }^{6}$. El tercer momento define, por el contrario, la determinación de las condiciones de una realización concreta de la relación entre religión y política. La razón hegeliana debe hacer la síntesis de las dos exigencias separadas por el entendimiento moderno: que religión y política sean diferentes y que, sin embargo, se den unidas en la realidad concreta. En este caso ideal, la religión funda la política, pero no determina su forma ${ }^{7}$. El espíritu absoluto se manifiesta

6 Son muy interesantes las apreciaciones que hace G. Amengual en relación con la evaluación hegeliana tanto del catolicismo como del luteranismo. A pesar de las críticas del Hegel de los últimos años de Berlín, Amengual señala cómo hay algunos aspectos del catolicismo bien vistos por Hegel, como es la valoración de la objetividad, la doctrina de la iglesia como fundamento de la fe y el interés por conciliar razón y fe. Al mismo tiempo que se aparta de algunos principios luteranos como la sola scriptura, la sola fides y la doctrina de los dos reinos: G. Amengual, Introducción en Hegel, G. W. F. , Escritos sobre religión, pp. 38-44.

7 Hegel, G. W. F. , Lecciones sobre la filosofía de la historia universal (Edición Lasson. Traducción de José Gaos), Alianza, Madrid, 1982, p. 112: «En este sentido se dice con razón que el Estado tiene su base en la religión». También Hegel, G. W. F. , Lecciones de filosofía de la historia (Edición Brunstädt. Traducción de José M $^{\mathrm{a}}$ Quintana), PPU, Barcelona, 1989, pp. 54-58. También Hegel, G. W. F. , Enciclopedia de las ciencias filosóficas en compendio, (traducción de R. Valls Plana), Alianza, Madrid, 2008, § 552, p. 572: «la sustancialidad de la eticidad y del Estado es la religión». También Hegel, G. W. F. , Principios de la filosofía del derecho, (traducción de J. L. Vermal), Edhasa, Barcelona, 1999, § 270 Obs. p. 392: «La religión es el fundamento del Estado, que contiene en sí lo ético en general y más precisamente la 
según la naturaleza propia del espíritu objetivo, de modo inmanente a su modo de existir ${ }^{8}$. De ahí que la fundación de lo político por la religión no viole su autonomía. Sin embargo, la justificación del Estado, su legitimidad, "consiste en que sea conocido como momento, como determinación de la naturaleza divina misma » ${ }^{9}$. Esta afirmación, central en la filosofía de Hegel hasta el final de su obra, va mucho más allá de una supuesta utilidad de la religión para el Estado y de un supuesto totalitarismo político.

¿Cómo abordar la intricada relación entre los diferentes momentos de manifestarse el espíritu, como espíritu subjetivo, espíritu objetivo y espíritu absoluto, en la que está implicada la relación entre religión y política en la filosofía de Hegel? Como se ha señalado la conciencia moral es un lugar privilegiado para realizar este abordaje. La hipótesis que sostengo es que la conciencia moral (Gewissen) es una figura del espíritu ${ }^{10}$ que representa una síntesis del espíritu subjetivo, pues es autoconciencia subjetiva, del espíritu objetivo, pues su contenido objetivo son los principios y deberes éticos, y del espíritu absoluto, pues en tanto conciencia moral somete tanto al mundo objetivo como a su representación a su propio juicio, con lo que se convierte en autoconciencia que queda cabe sí, es decir, que trasciende el espíritu objetivo ${ }^{11}$. El tratamiento de esta figura del espíritu nos permite abordar la relación entre religión y política en el contexto del sistema hegeliano de modo efectivo ${ }^{12}$.

naturaleza del Estado como voluntad divina, es al mismo tiempo sólo fundamento. El Estado es voluntad divina en cuanto espíritu presente que se despliega en una figura real y en la organización de un mundo».

8 Para entender bien esta afirmación, hay que tener en cuenta la afirmación especulativa de que el espíritu absoluto es el sujeto de la relación entre él y el espíritu objetivo, humano. Y no al revés. Esta relación se efectúa en su inmanencia de un modo jerarquizado. Así lo expone Bourgeois, B., Éternité et historicité de l'esprit selon Hegel, Vrin, Paris, 1991, p. 16.

9 Hegel, G. W. F., Lecciones sobre la filosofía de la historia universal (Edición Lasson), Alianza, Madrid, 1982, p. 112. Hay que notar que al hablar así Hegel está pensando en un efectivo «deber ser», es decir, de lo que es real, que ha tenido lugar en la forma del Estado protestante.

10 Es una figura del espíritu, no de la conciencia. Según Hegel las figuras del espíritu se distinguen de las de la conciencia en que «son espíritus reales, realidades propiamente dichas y, en lugar de figuras sólo de la conciencia, figuras de un mundo». Hegel, G. W. F., Fenomenología del espíritu, (traducción de M. Jiménez Redondo), Pre-textos, Valencia, 2009, p. 540. Las tres figuras del espíritu que expone ya en la Fenomenología son el mundo ético, espíritu extrañado de sí y un más allá y la moralidad.

11 Hegel, G. W. F., Fenomenología del espíritu, p. 782.

12 No se entrará aquí en detalle en la deducción que hace Hegel de la conciencia moral en los Principios de la filosofía del derecho §§ 136-138. Para un comentario de esta deducción se puede ver el artículo de Amengual, G., «La conciencia moral como el derecho supremo del sujeto", en: Paredes, M. C., Subjetividad y pensamiento. Cuestiones en torno a Hegel, Universidad de Salamanca, 1994, pp. 57-71. Aquí baste recordar lo que dice Hegel, G. W. F., Principios de la filosofía del derecho § 132 sobre el derecho de la voluntad subjetiva, a saber, que lo que la voluntad subjetiva «deba reconocer como válido, sea considerado por ella como bueno». 


\section{El ALUMBRAMiEnTo DEL ESPÍRITU ABSOLUTO EN LA CONCIENCIA}

El arte, la religión y la filosofía tienen el mismo contenido: lo verdadero, la unidad de lo subjetivo y lo objetivo. El espíritu absoluto se manifiesta en estas tres formas de darse un mismo contenido: la forma de la intuición sensible, la forma de la representación, la forma del concepto. Por ser el espíritu mediación consigo mismo, en ninguna de esas formas de darse el contenido de un modo efectivamente real está completamente ausente ninguna de las demás. De ahí que la supuesta superación de la religión en la filosofía en el sistema hegeliano, sea tan cuestionable ${ }^{13}$.

Pero además el espíritu absoluto se manifiesta en la objetividad ${ }^{14}$. El espíritu absoluto actúa tanto en la Filosofía del derecho - a través de la relación entre Estados-, como en la Enciclopedia —a través de los espíritus particulares de los pueblos-, en la historia universal. La historia es el medio más adecuado de manifestación del espíritu absoluto, aunque él no es su sujeto, sino los diferentes Volksgeist ${ }^{15}$. Ahora bien, de esa manifestación en la historia, no está ausente ni la conciencia subjetiva ni la Sittlichkeit. Por cómo se constituye la praxis misma del espíritu, ni los individuos ni los pueblos pueden ser considerados meros instrumentos del curso histórico, como si el espíritu fuera un proceso mecánico ${ }^{16}$. Más bien la mirada hegeliana nos

13 Avala esta afirmación la Introducción a la Historia de la Filosofía de 1820, donde afirma que la religión «no debe ser superada». Hegel, G. W. F. , Geschichte der Philosophie, «Berliner Niederschrift der Einleitung», Werke 20, Suhrkamp, Frankfurt, 1971, pp. 492-493.

14 Bourgeois, B., Éternité et historicité de l'esprit selon Hegel, p. 18. Bourgeois muestra cómo se trata de un paso de un momento del espíritu a otro y, por ello, existe entre ellos una interpenetración casi sustancial. Tal intimidad permite leer el paso de uno a otro indistintamente como obra de uno o de otro.

15 Hegel, G. W. F., Enciclopedia de las ciencias filosóficas en compendio § 552, p. 571: «naturaleza e historia están sirviendo solamente a la revelación del espíritu y son vasos de su gloria». En la Introducción a la filosofía de la historia Hegel nos ilustra del diferente modo de manifestarse en la historia el espíritu absoluto y el modo de actuar el espíritu objetivo. El siguiente texto nos sirve de buena muestra: «Por lo que hace pues al cotejo de las constituciones de los primitivos pueblos históricos, debemos concluir que, por así decirlo, no podemos deducir nada que nos ilumine sobre el principio último de la constitución y sobre el principio aplicable a nuestra época. En cambio respecto de la ciencia y del arte sucede muy de otro modo; por ejemplo, la filosofía de los antiguos es el auténtico fundamento de la moderna, hasta el punto de que ésta debe englobarla necesariamente, como suelo en el que se asienta. La relación entre ambas nos aparece como una ininterrumpida construcción del mismo edificio, puesto que la piedra fundamental, las paredes y el techo han venido siendo los mismos». Hegel, G. W. F., Lecciones de filosofía de la historia (Edición Brünstäd), PPU, Barcelona, 1989. P. 65.

16 Hegel, G. W. F., Lecciones de filosofía de la historia (Edición Brünstäd), PPU, Barcelona, 1989, p. 52: «No es precisamente en este sentido puramente externo que se relacionan los hombres, como medios, al fin de la Razón. Con éste y, con ocasión del mismo, no satisfacen tan sólo los fines de su particularidad, distintos de él en cuanto a su contenido, sino que tienen parte en aquel fin mismo de la Razón y son, justamente por eso, fines autónomos. Lo son no tan sólo formalmente, igual que los seres vivos, cuya existencia individual constituye ya 
invita a considerar que, tanto la conciencia moral y religiosa, como la eticidad son momentos de alumbramiento del mismo espíritu absoluto, que en sí mismo es "saber de la verdad eternamente real y efectiva ${ }^{17}$. Son lugar de su manifestación ${ }^{18}$. Este punto se clarifica al detenerse en los textos finales de la Fenomenología del Espíritu ${ }^{19}$. En ellos, aparece el deber como la esencia de la conciencia moral. Ella, que es moral y que es activa, cumple con el deber. Ahora bien, ese deber contiene como su ingrediente la misma autoconciencia individual. Se entiende como su cumplimiento: "la convicción individual y el saber de ese deber constituyen un momento absoluto de la moralidad ${ }^{20}$. Cuando el fin, que es declarado puro deber, se convierte en objetivo y, es por tanto, deber cumplido, entonces la conciencia individual se ve como realizada y puede gozar.

por su índole propia, algo que se subordina a la vida humana, y así con pleno derecho pueden ser tomados como medios; los hombres son fines autónomos también por el contenido mismo del fin. En esta determinación queda comprendido precisamente aquello que juzgamos que debe quedar excluido de la simple categoría de un medio: tal es el caso de la moralidad subjetiva y objetiva y de la religiosidad. El hombre es un fin en sí mismo únicamente gracias a lo divino que hay en él, gracias a aquello que desde el comienzo hemos denominado Razón y, en cuanto esta es activa y se autodetermina, hemos llamado libertad».

17 Hegel, G. W. F., Enciclopedia de las ciencias filosóficas en compendio § 552, p. 571. Como señala L. M. DE LA MAZA en "La religión como autoconciencia del espíritu en la "Fenomenología" de Hegel», Seminarios de Filosofía, vol. 12-13, (1999-2000), pp. 249-265, p. 257, la primera visión de conjunto del espíritu aparece sólo en la introducción a la religión, que es cuando el espíritu toma conciencia de sí.

18 El paso a la religión puede hacerse desde el Estado, desde el arte o desde la conciencia moral, como ocurre en la Fenomenología del espíritu. M. Álvarez Gómez subraya el texto de la Enciclopedia de 1827 en el que Hegel pone de manifiesto que la religión tiene a sus espaldas no sólo el arte, sino también el Estado. Ver Álvarez Gómez, M., «Armonía originaria de la religión y el Estado en G. W. F. Hegel», en Paredes, M. C., Subjetividad y pensamiento, p. 99. Y añade, que no parece de rigor el que a una esfera se de entrada por diferentes lados; sin embargo, la religión es un caso peculiar, por su razón de fin. Desde mi punto de vista, la consideración del espíritu como mediación consigo mismo o acto puro, empleando una terminología ajena a Hegel, permite efectivamente el acceso de una esfera a otra de diferentes modos dependiendo del aspecto que se considere. De hecho, en la Fenomenología del espíritu la religión parece tener a sus espaldas la conciencia moral.

19 Una revaloración de estos textos finales de la Fenomenología del Espíritu referidos a la religión lo ha realizado L. M. de la Maza en «La religión como autoconciencia del espíritu en la "Fenomenología" de Hegel», Seminarios de Filosofía, vol. 12-13, (1999-2000), pp. 249-265. Ahí señala cómo Hegel no concibe la religión como «una dimensión del hombre al lado de otras, sino más bien como la síntesis suprema de todas aquellas experiencias fundamentales que el hombre puede hacer acerca de la verdad», p. 249. Un detallado análisis de la conciencia moral lo ha realizado A. VIGo en: «Conciencia moral como figura del Espíritu. Una aproximación al análisis hegeliano del Gewissen en Phänomenologie des Geistes», en HeRRERo, M. y otros, Escribir en las almas: estudios en honor de Rafael Alvira, Eunsa, Pamplona, 2014, pp. 953-991. Además de su detallado análisis de la conciencia moral, es muy valiosa su aportación sobre los errores de la crítica de Hegel a la «concepción moral del mundo» y en particular a Kant.

20 Hegel, G. W. F., Fenomenología del espíritu, p. 706. 
La unidad de la pura conciencia y de la conciencia individual no es simplemente un deseo para el hombre o un fin posible, sino un presupuesto de la razón misma, una inmediata certeza de la razón ${ }^{21}$. Es decir, que la autoconciencia está autoexigida en la figura de la conciencia moral ${ }^{22}$. Esa conciencia realiza, por un lado, la armonía entre la sensibilidad y la moralidad, realizando así el fin último de la autoconciencia en la forma del ser para sí; y, por otro lado, la armonía entre la naturaleza y la moralidad, realizando así el fin último del mundo en la forma del ser en sí.

Esa conciencia moral, por otra parte, remite a una pluralidad de casos, de modo que, consecuentemente, surgen para ella una multiplicidad de deberes y de leyes morales. Este momento de la dispersión siempre ha de distinguirse de esa primera conciencia que conserva el puro deber como indiferencia frente a todo contenido determinado en su relación con la necesidad de determinación. La tragedia de la conciencia, lo que Hegel llama «el trastueque» en la Fenomenología, es por un lado, su aspiración a realizarse, es decir, a que aparezca un yo resultado del deber y la realidad, y, al mismo tiempo, por otro lado, su no querer desaparecer en esa resolución. Es decir, su tragedia es producida por la tensión entre esos dos momentos de la conciencia, que hacen que la única posibilidad de que siga existiendo la conciencia moral sea su no cumplimiento.

Esa tensión se muestra también en que, por un lado, la acción real, sólo es acción de una conciencia individual (einzelnes), es decir, sólo es algo particular, que acaba en algo contingente, pero, por otro lado, el fin (Zweck) que realiza es universal. Si no fuera así, la conciencia quedaría encerrada en la pura particularidad y frustraría su concepto. El fin que realiza ha de ser un fin último y, por tanto, va más allá del contenido de una acción particular y hay que colocarlo más allá y por encima de toda acción real ${ }^{23}$. Si la moralidad ha de existir, cada acción, pese a todas sus limitaciones de contenido, es siempre la ejecución del fin total, absoluto, que Hegel denomina bien supremo. Un fin, que, por otro lado, si ha de seguir existiendo la conciencia moral, no se va a realizar en absoluto y que, sin embargo, existe como lo dado a la conciencia (vorgegebene) ${ }^{24}$. Así se hace presente el absoluto a la conciencia ${ }^{25}$. Como Gewissen, la autoconcien-

21 Hegel, G. W. F., Fenomenología del espíritu, p. 707.

22 No hay que olvidar que el status lógico de la conciencia es relación (Verhältnis), como especifica Hegel en el § 131 de los Principios de la filosofía del derecho. Esto significa que en sí misma siempre está hablando de su contrapartida, el bien, que es lo sustancial de la conciencia.

${ }_{23}$ Así expresa Hegel esta idea en la Fenomenología del espíritu, p. 722: «porque moralmente no se puede realizar, sino lo mejor universal (das allgemeine Beste), es decir, porque lo que debe ejecutarse, esto es, lo que se debe realizar es lo mejor universal, es decir, porque el deber consiste en realizar lo mejor universal o lo óptimo universal, no se hará o no se realizará nada bueno».

24 Hegel, G. W. F., Fenomenología del espíritu, p. 733.

25 Quizás desde esta perspectiva se puede comprender mejor cómo es posible que la religión sea al mismo tiempo inmanente al mundo ético y trascendente, es decir, perteneciente a la esfera del espíritu absoluto. Esta es la dificultad sistemática que encuentra Nuzzo a la 
cia tiene certeza del contenido del deber, antes vacío. Gewissen es, por tanto, «aquello a donde la precedente Bewusstsein de la Moralität, carente de acción, ha transitado ${ }^{26}$.

La conciencia moral es, por tanto, real. En ella, el puro deber no se contrapone al yo, sino que «es sabido como no teniendo validez alguna en tal quedar separado del yo; ese universal es ahora la ley que es en virtud del yo, en vez de que el yo sea en virtud de ella ${ }^{27}$. El espíritu cierto de sí mismo se procura una determinación y lo hace en la certeza inmediata de sí mismo. Un individuo es consciente de que algo es un deber cuando está inmediatamente contenido en la certeza de sí mismo. Esto no implica arbitrariedad, sino más bien un saber de sí mismo. La superación de la diferencia entre la conciencia universal y el yo particular es lo característico de la Gewissen.

De esta manera ese yo no es solo ser para sí, sino ser para otro. La Gewissen abre el yo a la comunidad. Permite comportarse con los demás en términos de universalidad. La conciencia moral incluye el momento del ser reconocido por otro. Ahora bien, matiza inmediatamente Hegel en la Fenomenología, no hay que olvidar que ese reconocimiento viene de que el resultado de la acción que pone por obra la conciencia está conectado a un saber: «aquello que uno tiene el deber de hacer es lo universal de todas las autoconciencias, lo reconocido y, por tanto, algo que está ahí, algo que está siendo» ${ }^{28}$.

El tránsito de la conciencia moral al espíritu absoluto en la Fenomenología del espíritu viene por la presencia del bien supremo como fin de la conciencia y por la universalidad del reconocimiento. En esa majestad de la conciencia por la que ella está por encima de su saber y su querer en la medida en que se da el contenido que quiere, reconoce ella misma la voz de Dios:

«esa genialidad moral que sabe la voz interior de ese su inmediato saber como la voz de Dios, y, en cuanto en ese saber, de manera asimismo inmediata, sabe la existencia, esta genialidad moral es la potencia creadora de Dios que en su propio concepto porta la vida. Esa genialidad es a la vez en sí misma culto divino, servicio de Dios ${ }^{29}$.

En el reconocimiento y reconciliación, de cuya posibilidad es responsable la conciencia, se hace presente lo incondicionado, la misma divinidad. La conciencia moral se presenta entonces como conciencia religiosa en la medida en que siente y se representa el contenido verdadero sin llevarlo a concepto:

hora de encarar la cuestión de la religión en Hegel: «what is it that makes of religion, along with art and philosophy, a form of "absolute" spirit—an absoluteness that Hegel's systematics suggests should place it above and beyond objective spirit, that is, above and beyond the conflicts of politics and the finitude of world history? For, evidently, religion is not above and beyond history but deeply rooted in it; religion is not untouched by politics but problematically intertwined with it». Nuzzo, A., "Introduction», en id. Hegel on religion and politics, p. 5.

26 Hegel, G. W. F., Fenomenología del espíritu, p. 738.

27 Hegel, G. W. F., Fenomenología del espíritu, p. 740.

28 Hegel, G. W. F., Fenomenología del espíritu, p. 742

29 Hegel, G. W. F., Fenomenología del espíritu, p. 757. 
«La religión — dirá Hegel— es la forma de la conciencia de lo verdadero, tal como aparece a todo ser humano». ${ }^{30} \mathrm{Y}$ también, «la religión es conciencia del ser absoluto» ${ }^{31}$.

En la figura de la conciencia moral, la religión es conciencia del ser absoluto $^{32}$. Y esa conciencia religiosa no es diferente de aquella conciencia moral exigida por el deber: «no puede haber dos clases de conciencia, una ética y otra religiosa que se distingan entre sí en su haber y su contenido», dirá Hegel en la Enciclopedia ${ }^{33}$. Por la forma, sin embargo, a la conciencia religiosa, le corresponde la sanción de la ética. Aunque la eticidad se vuelque en la mundanidad, con todos sus condicionamientos, mientras que la conciencia religiosa queda al margen de ella.

La religión se presenta como teniendo por objeto el ser absoluto en y para sí, en la forma del sentimiento y la representación. La religión tiene un momento justificado de sentimiento casual, que se supera en la representación del contenido. Gefühl y Vorstellung se condicionan mutuamente: el sentimiento garantiza la participación subjetiva en el contenido representado, mientras que la representación posibilita al menos la crítica del contenido. Así se hace posible que el sentimiento confíe en el contenido de lo sentido. En realidad, según apunta Wagner, lo mismo ocurre con la relación entre representación y concepto, una vez que el contenido se ha elevado al pensamiento: de lo que se trata es de captar a un tiempo la Vorstellung y el Begriff en su mutua relación ${ }^{34}$.

Habrá personas que no puedan ir más allá de la representación que les proporciona la religión. La tarea de la filosofía de la religión es justamente la de «elevar», la de proporcionar un puente que lleve la representación religiosa hasta el pensamiento, hasta el concepto, hasta el saber.

Aunque es cierto que, como dice en la Enciclopedia con claridad, solo a partir de la eticidad es posible la verdadera religiosidad, porque solo a partir de ella deviene sabida la idea de Dios como espíritu libre y, por tanto, fuera del espíritu ético se buscará en vano la verdadera religión y religiosidad; también es cierto

30 Hegel, G. W. F., Enciclopedia de las ciencias filosóficas en compendio § 573. También ver Principios de la filosofía del derecho, § 270.

31 Hegel, G. W. F., Fenomenología del espíritu, p. 779.

32 En un texto cercano en el tiempo a la Fenomenología, de 1810, preparado para un grupo selecto de alumnos en Nürenberg, dice Hegel: «Este ser absoluto [Dios] está presente en nuestra conciencia pura y se nos revela en ella. El saber de él se encuentra en nosotros de manera inmediata, mediado a través de ella, y puede ser denominado fe». HEGEL, G. W. F., Doctrina del derecho, los deberes y la religión para el curso elemental, Edición de MaUREIRA, M. y Wrehde, K., Biblos, Buenos Aires, 2010, §72.

33 Hegel, G. W. F., Enciclopedia de las ciencias filosóficas en compendio § 552.

34 Wagner, F., o.c., p. 143. Como señala G. Amengual, efectivamente la religión y la filosofía refieren el mismo conocimiento, pero bajo una forma epistémica diferente. "Introducción», en Introducción a Hegel, G. W. F., Escritos sobre religión, p. 32. El libro de TheunisSEN, M., Hegels Lehre von absolutem Geist als theologisch-politischer Traktat, W. de Gruyter, Berlin, 1970, es una referencia esencial para comprender esta relación. 
que aquello a lo que se llega es absolutamente prius ${ }^{35}$. Estamos de nuevo ante un ejemplo de mediación recíproca de los diferentes momentos del espíritu ${ }^{36}$. Es decir, el espíritu absoluto no queda encerrado en una simple determinación del espíritu finito. Como sugiere Bourgeois, el desarrollo fenomenológico de la conciencia real es la refutación de todo reduccionismo humanista de la teoría hegeliana de la relación entre el espíritu objetivo y el espíritu absoluto ${ }^{37}$.

\section{El ALUMBRAMIENTO DEL ESPÍRITU ABSOLUTO EN LA ETICIDAD}

También la Sittlichkeit tiene su tarea en relación con la religión. La conciencia encuentra en ella la unidad entre lo objetivo y lo subjetivo, en que consiste su verdad y su libertad. El Estado es mediación para la determinación de la conciencia moral como espíritu de un pueblo que se manifiesta en una Sittlichkeit $^{38}$. La conciencia, moral y religiosa al mismo tiempo, está presente en el Estado y actúa en él. Es decir, que la forma efectivamente relevante en que aparece la religión en el Estado, es la religión como conciencia del ser absoluto ${ }^{39}$.

De ahí que la figura de la conciencia moral y religiosa sea el nudo gordiano del problema ${ }^{40}$. Esa forma de presentarse la religión a la conciencia, como conciencia de lo absoluto, implica una dislocación en el proceso mismo del espíritu hegeliano, pues parece que el espíritu absoluto quedara a través de la

35 Hegel, G. W. F., Enciclopedia de las ciencias filosóficas en compendio $§ 552$.

36 Bourgeois explica en concreto esta mediación diciendo que «la necesidad de esta determinación (de una determinación del absoluto) es la de un ser que lleva en sí todas las determinaciones, que han sido puestas con anterioridad, puesto que lo que es, se ha revelado ser necesariamente, en su contenido, todo lo que se muestra ahora como no pudiendo tener por sí mismo la forma del ser. Por eso el espíritu absoluto: 1) es, 2) hacer ser al espíritu objetivo, el cual no es por sí mismo» Bourgeois, B., o.c., p. 25.

37 Bourgeois, B., o.c., p. 26.

38 Así lo expresa Hegel con claridad en las Lecciones sobre la filosofía de la historia universal: «El Estado tiene con la religión un mismo principio común. Esta no sobreviene desde fuera para regular el edificio del Estado, sino que es la primera interioridad que en él se define y se realiza. (...) No debemos representarnos la relación como si la religión debiera sobrevenir posteriormente». HegEL, G. W. F., Lecciones sobre la filosofía de la historia universal, p. 113.

39 Hegel, G. W. F., Enciclopedia de las ciencias filosóficas en compendio § 554: «La religión, como se puede llamar a esta esfera suprema en general, hay que considerarla, tanto como saliendo del sujeto y encontrándose en él, como saliendo de modo objetivo del espíritu absoluto, el cual como espíritu está ya en la comunidad».

40 No lo sería, si se interpretara la conciencia al modo como lo hace el reduccionismo antropológico de Feuerbach, para quien la conciencia sería sagrada por ser ético-política y el espíritu absoluto no sería otra cosa que la absolutización ideal de la realidad finita del espíritu objetivo. Sin embargo, como dice Bourgeois, a quien ya se ha aludido en este punto: «il faut dire que le développement phénoménologique de la consciente réelle (...) est la réfutation préalable de tout reductionnisme humaniste de la théorie hégélienne du rapport entre l'esprit objective et l'esprit absolu». Bourgeois, B., o.c. p. 26. 
conciencia reducido a los límites de la eticidad. Sin embargo, la religión como conciencia del absoluto se representa a la persona singular como siendo libre, gracias al absoluto. Esta libertad de la persona fundada en lo absoluto, que en ella se manifiesta, une inextricablemente la religión con la eticidad del Estado, en la cual la libertad del individuo y de su conciencia está escondida en las instituciones y las leyes. La certeza de sí misma de la autoconciencia, como conciencia moral es la «efectiva realidad espiritual», la eticidad de un pueblo es «la efectiva realidad empírica», dirá Hegel en la Enciclopedia ${ }^{41}$.

En los Principios de la filosofía del derecho Hegel pone el énfasis en la necesidad de la determinación de la conciencia en los deberes concretos en el ámbito de la eticidad. El Estado representa para la conciencia el sistema objetivo de sus principios y deberes. Sin embargo, la conciencia moral conserva incluso en este caso su cierta independencia, que cosiste en su certeza, en asegurar que ella sabe a partir de sí qué sean el derecho y el deber. Y justamente es por esta unidad de su saber subjetivo con lo que es en sí y por sí, por lo que Hegel dice en los Principios de la Filosofía del Derecho que la conciencia es algo sagrado ${ }^{42}$.

Y, sin embargo, el Estado no puede reconocerla en la forma subjetiva en la que se presenta. Precisamente, porque lo que ella considera su verdad, puede ser juzgado desde fuera de ella misma. La conciencia ha de someterse al juicio de si es o no verdadera. Si no estuviera dispuesta a hacerlo, dejaría de responder a su concepto, a saber: ser la regla de un modo de actuar racional, universal y válido en y por sí. Dejaría, consiguientemente, de estar abierta al reconocimiento y abortaría la constitución de la comunidad política. A pesar de todo al final del § 137 de la Filosofía del derecho, donde Hegel expone estas ideas, añade que «la conciencia religiosa no pertenece a este ámbito». Sin embargo, como se ha señalado, hay razones más que sobradas para pensar que el tránsito de la conciencia moral a la religiosa no está interceptado en el pensamiento hegeliano, por muy sigiloso que se presente en algunos de sus textos. De hecho en el § 270 de la Filosofía del derecho no intercepta el tránsito entre el espíritu objetivo y el espíritu absoluto: el Estado es voluntad divina en la medida en que el espíritu absoluto se despliega en él como una figura real. En la Enciclopedia vuelve a subrayar este aspecto: «La sustancialidad de la eticidad y del Estado es la religión». ${ }^{43}$ Se podría decir que la eticidad es la sustancialidad de la voluntad libre, y consiguientemente de la conciencia moral, y la religión es la sustancialidad de la eticidad y el Estado. De ahí que Hegel insista en que el último fundamento sea la religión. Donde la religión se hace presente es ella también la instancia decisiva ${ }^{44}$.

\footnotetext{
41 Hegel, G. W. F., Enciclopedia de las ciencias filosóficas en compendio § 552.

42 Hegel, G. W. F., Principios de la filosofía del derecho § 137 Obs.

43 Hegel, G. W. F., Enciclopedia de las ciencias filosóficas en compendio $§ 552$.

44 Hegel, G. W. F., Enciclopedia de las ciencias filosóficas en compendio § 552 Obs, p. 573: «En tanto la religión es la conciencia de la verdad absoluta, resulta que todo lo que ha de valer como verdadero en el ámbito de la voluntad libre - solamente puede valer tanto cuanto tiene parte en aquella verdad-, está subsumido bajo ella y de ella se sigue».
} 
De hecho, cuando ese fundamento no se hace presente en la eticidad y el Estado, la conciencia deja de reconocerse en él y se toma su derecho. La realización de la legislación en esa circunstancia terminaría fracasando ante los ataques del espíritu religioso ${ }^{45}$. Algo tremendamente peligroso para la comunidad política. Aferrarse a la religión o a la conciencia religiosa hasta el punto de no querer comprometer la voluntad en los deberes del Estado, presagia ya la revolución. En ese caso, para esa conciencia, las leyes del Estado adquirirían la forma de lo negativo ${ }^{46}$.

Hegel presupone que en la humanidad civilizada, en la que las leyes y el Estado alcanzan una existencia racional, la conciencia religiosa no puede estar incómoda, precisamente, porque las instituciones y las leyes mismas tienen el mismo contenido que la religión. Siempre, por supuesto, que la religión sea verdadera $^{47}$. La mediación de la filosofía se hace imprescindible, para que la tensión entre religión y política sea mínima ${ }^{48}$.

Tanto en una religión supersticiosa que esclaviza al hombre, como en un Estado que ha abandonado la racionalidad, se generará una tensión entre religión y política de múltiples maneras. El Estado es la vida racional de la libertad autoconsciente y no un mero mecanismo exterior que agrega intereses. Por su parte, la doctrina religiosa no es puramente interior, algo solamente interno a la conciencia, sino que esa conciencia actúa, se exterioriza en el mundo y afecta al mismo núcleo de las instituciones y las leyes.

En resumen, la libertad de la autoconciencia se hace realidad efectiva en la coincidencia del contenido de la religión y la eticidad, y en el mantenimiento de la diferencia de la forma de darse ese contenido ${ }^{49}$. Respecto de la forma, la religión pertenece al ámbito de la interioridad, mientras que el Estado exige el deber jurídico del cumplimiento externo. El Estado pondría en peligro el dere-

45 Cfr. Álvarez Gómez, M., «El poder de la subjetividad en religión», en: Paredes, M. C., Política y religión en Hegel, (pp. 11-31), p. 12.

46 Hegel expresa este argumento, pero dado la vuelta. Hegel, G. W. F., Enciclopedia de las ciencias filosóficas en compendio § 552 Obs. p. 576: «Sólo cabe considerarlo como estupidez de los tiempos modernos pensar en trasmutar un sistema de eticidad corrompida, su constitución y legislación, sin cambiar la religión; es estúpido creer haber llevado a cabo una revolución sin reforma». Es decir, unas malas leyes suponen una mala religión y la reforma es entonces anterior a la revolución.

47 Hegel, G. W. F., Enciclopedia de las ciencias filosóficas en compendio $§ 552$ Obs.

48 En opinión de F. Wagner, es la filosofía la que puede mediar entre la libertad individual y la libertad común, entre el saber subjetivo de la religión y la realidad objetiva del Estado. WAGNER, F., o.c., p. 131. Es el argumento también del artículo citado de Ginzo.

49 Desde mi punto de vista esta afirmación no licita sin más el hablar de una «religión civil» en la filosofía del derecho hegeliana, como hace A. Buchwalter, por mucho que buscando una ampliación del significado de esa expresión, se refiera a la deseable confluencia de religión y política y a la deseable separación de iglesia y Estado en el planteamiento de Hegel. Comparto, sin embargo, con Buchwalter su incidencia en el aspecto republicano de la religión en el planteamineto de Hegel. Buchwalter, A., «The Relationship of Religion and Politics under Conditions o Modernity and Globality. An Hegelian Account», An International Journal in Philosophy, Religion, Politics and the Arts, Vol. 1 (2006). 
cho de la interioridad si planteara sus exigencias de modo religioso. También la iglesia trasformaría la religión en un régimen tiránico si impusiera sus deberes de un modo jurídico. La forma ha de mantenerse siempre diferenciada. La religión, por tanto, «no puede hacerse valer en el Estado según su forma ${ }^{50}$. Sin embargo, a ella, por su forma "compete la sanción de la eticidad residente en la efectiva realidad empírica. De esta manera, la religión es para la autoconciencia la base de la eticidad y del Estado» ${ }^{51}$.

Una vez más es preciso recordar que eso es así siempre que ambos, religión y Estado, tengan la forma de la racionalidad. Si el Estado es un Estado «meramente existente», es decir, que no se ha desarrollado conforme a la idea ${ }^{52}$, entonces pierde su derecho frente a la conciencia moral. Así lo dice con claridad Hegel en Principios de la filosofía del derecho § 138:

«La dirección de buscar en el interior de sí y de saber y determinar a partir de sí mismo lo que es justo y bueno, aparece en épocas en las que lo que rige como tal en la realidad y las costumbres no puede satisfacer una voluntad superior; cuando el mundo de la libertad existente le ha devenido infiel, aquella voluntad ya no se encuentra a sí misma en los deberes vigentes y debe de tratar de conquistar en la interioridad ideal la armonía que ha perdido en la realidad»..53

50 Hegel, G. W. F., Principios de la filosofía del derecho $\S 270$ Obs.

51 Hegel, G. W. F., Enciclopedia de las ciencias filosóficas en compendio $\$ 552$.

52 El mismo Hegel habla en ese sentido de la época de los pueblos germánicos. Hegel, G. W. F., Principios de la filosofía del derecho § 358.

53 Hegel, G. W. F., Principios de la filosofía del derecho § 138, p. 237. Este argumento podría quizás ser superado desde la perspectiva de la filosofía de la historia. Es decir, si hubiera un punto final histórico-empírico que se corresponda definitivamente con el concepto. También en ese caso será la conciencia la que juzgue la adecuación. Entre tanto Hegel afirma que habrá «épocas» en que al individuo le esté permitido huir de la realidad hacia su vida interior. De hecho, se podría decir que fuera del Estado moderno cristiano protestante esa posibilidad es sin duda la más probable. De todas maneras, la cuestión aquí no es de filosofía de la historia, sino conceptual: cómo debemos pensar la conciencia moral y su relación con la religión y la política en la filosofía hegeliana para que la posibilidad socrática se pueda dar empíricamente, como él mismo constata. Un texto revelador que completa esta visión es el siguiente: «Pero, como se dijo, la religión y el Estado pueden tener leyes diferentes, porque el terreno de ambos es diverso, y, sin embargo, puesto que el terreno de ambos es a la vez el mismo, el sujeto, ellos pueden llegar hasta la contradicción. La religión exige santidad, el Estado, eticidad (...) Cuando la religión exige así al hombre cosas que están en contra de lo racional que hay en el Estado, la conciencia racional entra a combatirlo en cuanto que ella es, en el sentido más propio, sabiduría del mundo, es decir, conocimiento de lo que es racional en la realidad y en el presente. Tal religión se comporta frente a lo real, de modo puramente negativo, y entonces todas las organizaciones positivas de la eticidad carecen de derecho y la voluntad del hombre tampoco es reconocida como libre y adulta. (...) Un Estado configurado según el principio de libertad debe entrar en conflicto con una religión de la no libertad, que no reconoce sus instituciones libres, pero cuando la religión cede resulta una intrínseca carencia de verdad». Hegel, G. W. F., Lecciones sobre filosofía de la religión I, (traducción de Ricardo Ferrara), Alianza Editorial, Madrid, 1984, pp. 341-342. Se ve perfectamente en este texto la tragedia del desacoplamiento entre religión y eticidad para Hegel, pero también la posibilidad de la tensión mantenida por la conciencia, que es deseable para que el acuerdo, si llega, sea efectivo. 
Este texto recuerda a la imagen del héroe que dibuja en las lecciones de filosofía de la historia ${ }^{54}$. De esta afirmación se infiere que no toda concreción histórica de la Sittlichkeit es conforme a la idea y, por tanto, que no toda realización histórica está inmediatamente justificada ${ }^{55}$. Cuando eso ocurre, la conciencia religiosa presenta su resistencia frente a la eticidad y la religión es la instancia orientadora de esa conciencia en la determinación de su actuar ${ }^{56}$.

$\mathrm{Si}$, en esta circunstancia, la objetividad de esa conciencia no se constituye en el Estado, sino en las iglesias, aparece el clásico problema de la lucha de instancias, que Hegel soluciona con una total separación entre Iglesia y Estado y un completo respeto entre ambos en la Filosofía del derecho y en una identificación en el estado protestante en la Enciclopedia. Ahora bien, siempre que no estemos en presencia de esa forma culminada de existencia política, parece que vale lo que dice en la filosofía del derecho.

En el § 270 de los Principios de la filosofía del derecho declara que el Estado no puede inmiscuirse en el contenido de la religión, en la medida en que éste se refiere a la intimidad de la representación. Ha de ser incluso tolerante y soportar comunidades que no reconozcan los deberes respecto al Estado e incluso pasar por alto hechos singulares que le puedan afectar.

Lo mismo ocurre por el lado de la religión: para que lo ético sea consecuencia de la religión, ésta ha de tener un contenido verdadero, es decir, una verdadera idea de Dios. Eso no ocurre en opinión de Hegel, ni en las supersticiones, ni en la religión católica. Si la religión se aísla en su unilateralidad, "puede llegar a corromperse hasta la opresión del espíritu y su libertad ${ }^{57}$. No obstante,

54 Hegel, G. W. F., Lecciones de filosofía de la historia, p. 49: "Los grandes hombres en la historia son estos cuyos fines particulares encierran lo substancial que es la voluntad del Espíritu del mundo. Debe llamárselos héroes en tanto que sacan sus fines y su vocación no simplemente del tranquilo y ordenado transcurso de las cosas, consagrado por el sistema que las mantiene estables, sino de un manantial cuyo contenido es recóndito y no ha brotado hasta una existencia actual; del Espíritu interior, que es todavía subterráneo, y que aldabonea al mundo exterior como a una cáscara y la hace estallar, porque él es otra almendra que la de esa cáscara. Tales héroes pues parecen beber de sí mismos, y sus acciones han creado en el mundo una situación y unas circunstancias que parecen ser tan solo su hecho y su obra».

55 Hegel, G. W. F., Lecciones de filosofía de la historia (Edición Brunstäd), PPU, Barcelona, 1989, p. 54: «hay, en las concreciones de lo fenoménico mucho que podría ser censurado». P. 55: "sólo lo que de este plan se lleva a efecto (el plan de Dios) tiene realidad, siendo no más que corrupta existencia cuanto no es conforme al mismo».

56 Esta afirmación de la filosofía del derecho imposibilita el interpretar la filosofía de Hegel según una determinación absoluta de la conciencia por parte de la eticidad. Si eso fuera así, la conciencia propiamente desaparecería una vez que está establecida la eticidad y esto no ocurre, como se ve en la posibilidad apuntada en ese texto. Es la interpretación que hace, entre otros, Tugendhat, E., Autoconciencia y autodeterminación, Fondo de Cultura Económica, Méjico, 1993, pp. 271-273: «Hegel no admite la posibilidad de una relación crítica, autoresponsable con la comunidad o con el estado. Más bien lo que se nos dice es que las leyes existentes tienen una absoluta autoridad (...) La conciencia moral privada del individuo tiene que desaparecer». Y en la p. 274 alude a que la filosofía de Hegel es una filosofía de la justificación de lo existente.

57 Hegel, G. W. F., Enciclopedia de las ciencias filosóficas en compendio $§ 552$. 
como ya se ha señalado, Hegel entiende que habitualmente la mediación de la eticidad respecto de la religión es un hecho. Generalmente es a partir de la eticidad como se aprende y se llega a la religión ${ }^{58}$.

\section{CONCLUSIÓN: LA CONCIENCIA MORAL COMO MANIFESTACIÓN DEL ESPÍRITU}

La conciencia moral es expresión del espíritu subjetivo, actúa como espíritu objetivo y es manifestación del espíritu absoluto. Siendo ella la «realidad efectiva espiritual», se encuentra «encerrada» en los límites de la realidad efectiva empírica, la cual posee siempre el elemento de positividad, que es contingente. Esta es su tragedia. Y, sin embargo, como bien ve Amengual, el Estado, no sólo debe reconocerla, sino «que vive gracias a ella, en el sentido de que es ético y no puramente un mecanismo legal, gracias a ella $»^{59}$. La figura de la conciencia moral es el lugar efectivo en el que se resuelve la tensión o la reconciliación entre la religión y la política en el pensamiento de Hegel. La tensión o reconciliación dependerá de las concretas formas históricas de darse tanto la Sittlichkeit como la misma religión. En cualquier caso, la relación entre religión y política pasa por la certidumbre subjetiva y estará, por tanto, siempre marcada por la labilidad.

Universidad de Navarra

MonTSERrat Herrero

Instituto Cultura y Sociedad/Departamento de Filosofía

mherrero@unav.es

[Artículo aprobado para publicación en diciembre de 2014]

58 Hegel, G. W. F., Enciclopedia de las ciencias filosóficas en compendio § 552.

59 Amengual, G., op. cit, p. 65. 